\title{
Genetic Diversity and Pedigree Analysis of Muscadine Grape Using SSR Markers
}

\author{
Shanshan Cao \\ Department of Horticulture, University of Georgia - Tifton Campus, 2360 Rainwater Road, Tifton, GA \\ 31793 \\ Stephen Stringer \\ U.S. Department of Agriculture, Thad Cochran Southern Horticultural Laboratory, 810 Highway 26, \\ Poplarville, MS 39466
}

Gunawati Gunawan

Department of Horticulture, University of Georgia - Tifton Campus, 2360 Rainwater Road, Tifton, GA 31793

\author{
Cecilia McGregor \\ Department of Horticulture, University of Georgia, 1111 Plant Science Building, Athens, GA 30602
}

Patrick J. Conner

Department of Horticulture, University of Georgia - Tifton Campus, 2360 Rainwater Road, Tifton, GA 31793

Additional INDEX words. cultivar, DNA fingerprinting, identification, microsatellites, Muscadinia, Vitis rotundifolia

\begin{abstract}
Muscadine grape (Vitis rotundifolia) is the first native North American grape to be domesticated. During the past century, breeding programs have created a large collection of muscadine cultivars. Muscadine cultivars are usually identified by evaluating morphological traits and checking breeding records, which can be ambiguous and unauthentic. During this study, simple sequence repeat (SSR) markers were used to generate DNA fingerprinting profiles to identify muscadine cultivars and verify their reported pedigrees. Eighty-nine Vitis accessions were genotyped using 20 SSRs from 13 linkage groups. From these, 81 unique subgenus Muscadinia accessions were identified, and a core set of five SSR markers was able to distinguish all of them. Eighteen misidentifications were found, and five previously unknown accessions were matched with cultivars in the dataset. The profiles of 12 cultivars were not consistent with their reported parentage-progeny relationships. Genetic diversity was analyzed at four levels: all $V$. rotundifolia cultivars $(N=67)$; current cultivars $(N=39)$; historical cultivars $(N=28)$; and wild $V$. rotundifolia accessions $(\mathrm{N}=9)$. There was substantial genetic diversity in both wild and historically cultivated muscadines. The principle coordinate analysis (PCoA) showed clear separation among subgenus Vitis cultivars, wild muscadine accessions, and cultivated muscadines, with PCoA1 and PCoA2 explaining 11.0\% and 9.3\% of the total variation, respectively.
\end{abstract}

The genus Vitis is commonly recognized as having two subgenera, Vitis (bunch grapes) and Muscadinia (muscadine grapes) (Planchon, 1887). Although there has been long-standing controversy regarding their taxonomic distribution (Ingrouille et al., 2002; Pelsy, 2007), recent extensive phylogenetic studies strongly support the nomenclature of Muscadinia as a separate subgenus within Vitis (Liu et al., 2016; Wen et al., 2018; Zecca et al., 2012). Compared with the subgenus Vitis, the subgenus Muscadinia is much smaller and consists of only two identified species: $V$. rotundifolia and $V$. popenoei (Wen, 2007). V. munsoniana, once considered a third species

Received for publication 29 Oct. 2019. Accepted for publication 13 Dec. 2019. Published online 19 March 2020.

We thank the Southern Region Small Fruit Consortium for funding this work. We also thank the U.S. Department of Agriculture National Clonal Germplasm Repository located in Davis, CA (NCGR-D), the breeding group at North Carolina State University, and several private nurseries and vineyards for providing plant material.

P.J.C. is the corresponding author. E-mail: pconner@uga.edu.

This is an open access article distributed under the CC BY-NC-ND license (https://creativecommons.org/licenses/by-nc-nd/4.0/). within Muscadinia (Husmann and Dearing, 1916), was recently assigned variety status as $V$. rotundifolia var. munsoniana (Moore, 1991). V. rotundifolia var. rotundifolia (hereafter referred to as $V$. rotundifolia), is the only commonly cultivated Muscadinia grape; the name "muscadine" is exclusively reserved for $V$. rotundifolia, which is used by the muscadine grape industry of the southeastern United States to produce fresh fruit, juices, and wine (Olien, 1990). Muscadine grapes are morphologically distinct from bunch grapes because of their smaller clusters, unbranched tendrils, an abscission zone between the fruit and rachis, smooth thin bark, prominent lenticels, continuous pith, and berries with thick skins and unique fruity aroma (Hedrick et al., 1908; Munson, 1909). Genetically, Muscadinia species $(2 n=40)$ have two more somatic chromosomes than the subgenus Vitis species $(2 n=38)$ (Patel and Olmo, 1955).

Muscadine grapes were first cultivated in North America in the 16th century by European settlers; they were first commercially grown in the middle of 18th century (Husmann and Dearing, 1916). The first large-scale muscadine breeding program was initiated in North Carolina in 1907, and this program 
later released the first hermaphroditic muscadine cultivars (Dearing, 1948). During the past century, breeding efforts at several locations have led to a large number of muscadine cultivars and hybrids (Goldy and Onokpise, 2002). Cultivar identification and pedigree verification are essential to facilitate breeding programs and maintain the germplasm because the plants are typically propagated by rooting cuttings, and breeding germplasm consists of many closely related cultivars. However, many cultivars, especially more recent releases, are only documented via morphological characteristics, which are environmentally sensitive and challenging to differentiate. Therefore, a molecular marker-based database is necessary to facilitate cultivar identification and validate pedigree information. Among the many types of DNA molecular markers, simple sequence repeats (SSRs), also known as microsatellites, are characterized by high abundance, codominant inheritance, excellent reproducibility, and amenability to automated scoring with software, making them ideal markers for DNA fingerprinting (Nybom et al., 2014; Semagn et al., 2006). The high level of polymorphism at each marker even among full siblings makes SSRs very useful for identifying parent-progeny relationships (Bassil et al., 2012). SSR markers have been used to identify cultivars, verify pedigrees, and study genetic diversity in many clonally propagated crops, including bunch grape (Dangl et al., 2001; Franks et al., 2002; This et al., 2006), blackberry [Rubus subgenus Rubus sp. (Zurn et al., 2018)], black walnut [Juglans nigra (Dangl et al., 2005)], olive [Olea europaea (Cipriani et al., 2002; Trujillo et al., 2014)], poplar [Populus sp. (Fossati et al., 2005)], and vegetatively propagated turf bermudagrass [Cynodon sp. (Wang et al., 2010)]. The identities of 35 muscadine cultivars were verified with 14 SSRs (Riaz et al., 2008). However, the muscadine cultivar panel was primarily obtained from the U.S. Department of Agriculture (USDA) National Clonal Germplasm Repository located in Davis, CA, which is largely limited to older cultivars and lacks many recent releases.

The primary objective of this study was to develop an SSRbased molecular database for a wide range of current and historically important muscadine cultivars. This database will be a tool for the authentic identification of muscadine cultivars, thus contributing to improvements in muscadine germplasm management. The secondary objective was to understand genetic diversity in muscadine germplasm.

\section{Materials and Methods}

Plant material. During Summer 2017, leaf samples were collected from several germplasm collections, including the University of Georgia Tifton Campus (Tifton, GA), North Carolina State University (Raleigh, NC), Mississippi State University McNeill Research Unit (McNeill, MS), USDA National Clonal Germplasm Repository (Davis, CA), and a few private vineyards or nurseries. A total collection of 190 accessions was used in this study (Supplemental Table S1). Because most muscadine cultivars are not represented in a verified germplasm collection, at least two separate accessions from different locations for each cultivar were obtained when possible, and these were given separate numbers after the sample name (Supplemental Table S1). The whole collection consisted of 159 named $V$. rotundifolia accessions, five unknown $V$. rotundifolia accessions, five wild $V$. rotundifolia accessions, six $V$. rotundifolia var. munsoniana accessions, one
$V$. popenoei accession, seven hybrid accessions, five $V$. vinifera reference accessions, and two $V$. $\times$ labruscana reference accessions.

DNA EXTRACTION AND SSR GENOTYPING. DNA extraction of leaf tissue was performed as described previously (Conner et al., 2017). SSR amplifications were conducted using a threeprimer procedure (Steffens et al., 1993). Amplifications were conducted in a $25-\mu \mathrm{L}$ solution containing $16.8 \mu \mathrm{L} \mathrm{H}_{2} \mathrm{O}, 2.5 \mu \mathrm{L}$ 10X Buffer, $0.3 \mu \mathrm{L}$ Taq DNA polymerase (Genescript, Grand Cayman, Cayman Islands), $0.5 \mu \mathrm{L} 10 \mathrm{~mm}$ dNTPs, $1 \mu \mathrm{L} 10 \mathrm{~mm}$ universal fluorescent dye-labeled primer, $0.4 \mu \mathrm{L} 10 \mathrm{~mm}$ SSR forward primer, $1.5 \mu \mathrm{L} 10 \mathrm{~mm}$ SSR reverse primer, and $2 \mu \mathrm{L} 5$ $n g \cdot \mu \mathrm{L}^{-1}$ DNA template. During our experiment, the universal dye-labeled primer was conjugated with the M13 (TGTAAAACGACGGCCAGT) (Steffens et al., 1993) or the Tail C (CAGGACCAGGCTACCGTG) (Blacket et al., 2012), which have the same function but different sequence.

Amplifications were performed in a thermal cycler (Eppendorf Scientific, Westbury, NY) with a $55{ }^{\circ} \mathrm{C}$ touchdown program $\left[94^{\circ} \mathrm{C}, 3 \mathrm{~min}, 10\right.$ cycles $\left(94{ }^{\circ} \mathrm{C}, 30 \mathrm{~s} ; 55^{\circ} \mathrm{C}, 1 \mathrm{~min}\right.$; $72{ }^{\circ} \mathrm{C}, 1 \mathrm{~min}$ ), with each cycle decreasing $0.5^{\circ} \mathrm{C}$ at the second step starting from $55^{\circ} \mathrm{C}$, followed by 20 cycles $\left(94^{\circ} \mathrm{C}, 30 \mathrm{~s}\right.$; $\left.\left.50{ }^{\circ} \mathrm{C}, 1 \mathrm{~min} ; 72^{\circ} \mathrm{C} 1 \mathrm{~min}\right)\right]$. Polymerase chain reaction (PCR) products were sent to the University of Arizona Genetics Core (Tucson) for fragment analysis using a DNA analyzer (ABI3730; Thermo Fisher Scientific, Waltham, MA). A total of 66 Vitis-based SSR markers were screened for possible inclusion in this study (Supplemental Table S2).

DAta Analysis. Allele sizes were estimated manually in Geneious (v11.1; Biomatters, Newark, NJ) using peak sizes in the Microsatellite Plugin (v1.4.6, Biomatters). Genotyping was repeated three times if the allele size was ambiguous. GeneAlEX 6.5 (Peakall and Smouse, 2012) was used to identify duplicate genotypes, including both synonyms (accessions with a different name but identical genotypes) and homonyms (accessions with the same name but different genotypes). Duplicates of a cultivar with missing data at one or two loci but identical at all other loci were considered the same, and the one with the least missing data was retained to represent that cultivar. When the representative accession was chosen, data from the other accession(s) of that cultivar were used to complete the missing locus of the chosen representative if necessary. The dataset of unique genotypes was then analyzed with MicroChecker v2.2.3 (Van Oosterhout et al., 2004) to identify genotyping errors due to null alleles (nonamplified alleles), short allele dominance (large allele dropout), and the scoring of stutter peaks. After SSR markers with genotyping errors were removed, the reported pedigree for all cultivars was verified using a first-order parentage analysis, wherein cultivars with putative parent-progeny relationships should share one common allele at all loci; otherwise, an error in cultivar identification or reported pedigree was assumed. Therefore, the assumed identities of the cultivars were also verified again by evaluating pedigree relationships. Several factors were considered to determine the true identity of synonyms. First, when possible, the phenotype was accessed, primarily flower sex, berry color, and berry size. If multiple accessions were available, then the most commonly used accession name was considered correct. Finally, the parent-offspring relationship was evaluated, with primary consideration given to maternal-offspring relationships because they are not influenced by accidental 
pollination. A similar process was used for phenotype and pedigree evaluations to determine the true identity of homonyms. Additionally, if one homonym was also a synonym of another clone with multiple accessions, then the identity of that homonym was considered to be the clone with the most accessions. The homonym with the least supporting evidence of the true identity was then labeled as "unknown," followed by a unique identifying number.

Genetic diversity was analyzed at four levels: all $V$. rotundifolia cultivars; current $V$. rotundifolia cultivars; historical $V$. rotundifolia cultivars; and wild $V$. rotundifolia accessions (Supplemental Table S1). Historical cultivars were cultivars released before 1970, whereas current cultivars were released after 1970. The year 1970 was chosen because all leading cultivars in the southeast were released on or after this date (Mortensen, 2001). Parameters such as the number of alleles detected $(\mathrm{Na})$, number of effective alleles $(\mathrm{Ne})$, observed heterozygosity $(\mathrm{Ho})$, expected heterozygosity $(\mathrm{He})$, and probability of identity among siblings (PIsibs) were calculated using GeneAlEX 6.5. Ho was the proportion of individuals in a population that was heterozygous at a given locus. He was the percentage of samples that were heterozygous as expected under random mating (Nei, 1987). Polymorphism information content (PIC) referred to the value of the marker for detecting polymorphisms in a population, and it was calculated using CERVUS v3.0.7 (Hearne et al., 1992; Slate et al., 2000). The method of Smouse and Peakall (1999) was used to calculate the genetic distance matrix, which was used to conduct the principal coordinate analysis (PCoA) in GeneAlEX 6.5.

\section{Results and Discussion}

SSR MARKER AMPLIFICATION AND SELECTION. A survey of 66 Vitis-based SSR markers was conducted for a subset of 24 genotypes to determine those most useful for discriminating this germplasm. Included in the surveyed markers were five SSRs used in the Vitis International Variety Catalogue (VIVC) database (VVMD5, VVMD7, VVMD27, VVS2, and VrZag62) and all the SSRs previously used to fingerprint muscadine cultivars (Riaz et al., 2008) except for VVIN16, which displayed low heterozygosity in muscadine. Fingerprint analysis with 24 SSRs was conducted using the complete set of accessions. Excluded markers had poor amplification, multiple loci, or lacked polymorphism among the subset of accessions used to screen markers (Supplemental Table S2). The marker VMC8d11 located on LG20 produced two amplified loci with a difference of $\approx 100$ bp between amplification products (Supplemental Table S3). Both loci had easy-to-score peaks, and they were treated as two different loci named VMC8d11-1 and VMC8d11-2. Six SSR markers (VMC7h3, VMC4c9, VVIM63, VMC6e1, VVMD5, and VMC7c3) possibly contained null alleles (indicated by Micro-Checker v2.2.3, data not shown). No marker had large allele dropout (preferential amplification of the smaller allele), but VMC7c3 had stuttering peaks (amplification products that are one or two repeats shorter than the correct band size). Several individuals with homozygous null alleles (no amplification products) were found using VMC7h3, VMC6e1, and VMC7c3 after three amplification attempts. Additionally, genotypes at the locus of VVIM63 did not match the expected parent-progeny relationship unless a null allele was hypothesized, thus verifying the presence of null alleles for this locus. Neither of these issues was found for VVMD5 and $\mathrm{VMC} 4 \mathrm{c} 9$; therefore, $\mathrm{VMC} 7 \mathrm{~h} 3$, VVIM63, VMC6e1, and VMC7c3 were discarded due to the presence of null alleles, but VVMD5 and VMC4c9 were retained, leaving 20 markers from 13 different linkage groups for the fingerprint analysis (Table 1).

There were 190 accessions in the original dataset; however, removing the multiple accessions for 56 cultivars and 14 identified synonyms reduced the dataset to 89 unique genotypes (Supplemental Table S3) consisting of 82 Muscadinia genotypes, 2 Muscadinia $\times$ Vitis hybrids (Southern Home and Razzmatazz), and 5 subgenus Vitis accessions (Arkansas 1 was identified as a Vitis cinerea vine). After removal of the subgenus Vitis accessions, 84 
unique genotypes (including 82 Muscadinia genotypes and 2 Muscadinia $\times$ Vitis hybrids) identified in this study produced 239 alleles (Table 1). The number of alleles per locus ranged from 4 (VVMD34) to 20 (VMC4f3.1), with an average of 12. The average number of alleles per locus for the 14 SSRs used by Riaz et al. (2008) was 13, which was slightly higher than our measurement. The PIC value ranged from 0.28 (VMC4c9) to 0.81 (VVIB23), with a mean of 0.69. Except for VMC4c9, the other 19 SSR locus used in the study had a PIC value more than 0.5 , indicating that these SSRs are valuable for detecting polymorphisms within a population (Botstein et al., 1980).

IDENTIFICATION OF FIVE UNKNOWN PLANTS. For the 84 unique genotypes (82 Muscadinia genotypes and 2 Muscadinia $\times$ Vitis hybrids), the probability of identity $(P I)$ value was $3.0 \times 10^{-20}$, and the probability of identity among siblings measurement was $2.3 \times 10^{-8}$. Therefore, the probability that any two individuals matches at all 20 SSR loci by chance is 3 in $10^{19}$ if siblings are not considered, and $\approx 1$ in 40 million if siblings are considered. Hence, the matches identified in the dataset were convincing, and a DNA database using the 20 SSR markers robustly differentiated cultivars and even siblings.

Five unknown or uncertain identities were included in the initial dataset [Table 2 (no. 1-5)]. "Hinnant unknown" had a profile identical to 'Summit', and "Lineberger unknown" was identical to 'Triumph'. 'Lineberger Sport' was found in a planting of 'Nesbitt' and was thought to be either a sport with a larger berry size or an unknown cultivar. The SSR profile of this accession was identical to 'Nesbitt', ruling out that it is an unknown cultivar and providing evidence that it could be a sport of Nesbitt.

Although most native vines produce dark berries, rare bronze (nonpigmented mutation) grapes were proven superior

Table 2. Original name, collection location, and verified name of previously unknown (no. 1-5) and misidentified (no. 6-23) muscadine vines.

\begin{tabular}{llll}
\hline No. & \multicolumn{1}{c}{ Original sample name } & \multicolumn{1}{c}{ Collection location } & Verified name \\
\hline 1 & Hinnant unknown & NCSU & Summit \\
2 & Lineberger unknown & NCSU & Triumph \\
3 & Lineberger Sport & NCSU & Nesbitt \\
4 & CH Bronze 1800s Heirloom Bh & NCSU & Scuppernong \\
5 & CH Bronze 1800s Heirloom M & NCSU & Scuppernong \\
6 & Burgaw(1) & NCSU & Tarheel \\
7 & Carlos(1) & Private nursery, Concord, GA & Triumph \\
8 & Granny Val(4) & Private vineyard, Wray, GA & Fry \\
9 & Hunt(2) & Private nursery, Brooks, GA & Cowart \\
10 & Magnolia(1) & UGA & Carlos \\
11 & San Jacinto(1) & NCSU & James \\
12 & San Jacinto(2) & UGA & James \\
13 & La Salle(1) & NGA & James \\
14 & La Salle(2) & Private nursery, Concord, GA & James \\
15 & Scuppernong(1) & MSU & Roanoke \\
16 & Scuppernong(3) & Private nursery, Brooks, GA & Hunt \\
17 & Southland(2) & UGA & Darlene \\
18 & Sweet Jenny(2) & NCGR-D (DVIT 1779) & Vitis cinerea \\
19 & Arkansas 1 & MSU & Unknown(1) \\
20 & Dulcet(1) & NCSU & Unknown(2) \\
21 & Dulcet(2) & NCSU & Unknown(3) \\
22 & Tara(6) & NCGR-D (DVIT 2183) & Unknown(4) \\
23 & Triumph(6) & Cand & \\
\hline
\end{tabular}

${ }^{\mathrm{z}} \mathrm{NCSU}=$ North Carolina State University, Castle Hayne; UGA = University of Georgia, Tifton; NCGR-D = U.S. Department of Agriculture, National Clonal Germplasm Repository, Davis, CA; MSU $=$ Mississippi State University McNeill Research Unit, McNeill, MS. for making wine due to improved storability, and the bronze mutants were predominantly selected for early cultivation (Olien, 2002). The outcome of early cultivation was the proliferation of bronze fruit being grown on numerous farms; of all the names given to these early bronze fruit, "Scuppernong" became the common vernacular (Reimer, 1909). Eventually, the name Scuppernong was used to refer to all bronze muscadines, whereas "muscadine" was used to refer to vines that had pigmented berries. However, it is unclear whether all cultivars grown as Scuppernong are descended from the same original plant. Two of the unknown accessions, ' $\mathrm{CH}$ Bronze Heirloom Bh' and ' $\mathrm{CH}$ Bronze Heirloom M', were female bronze vines collected from home sites and dated back to the 1900 s, with unknown origin. Both of these accessions had the same profile as 'The Mother Vine', which originated from a clone of the supposedly original 'Scuppernong' vine in Roanoke, NC. In addition to these two unknown accessions, six accessions of 'Scuppernong' were tested. Four of these vines were identical to 'The Mother Vine' and are assumed to be the original 'Scuppernong' cultivar (Supplemental Table S1), and two accessions were identified as a released cultivar (Roanoke). Therefore, we found no evidence for more than one original 'Scuppernong' vine having been propagated from the wild.

Discovery OF 18 MisidentifiCATIONS. Eighteen accessions were found to have been misidentified [Table 2 (no. 6-23)]. Two 'Burgaw' accessions were tested, 'Burgaw(1)' from North Carolina State University (Castle Hayne, NC) and 'Burgaw(2)' from Mississippi State University (McNeil, MS) (Supplemental Table S1). These two accessions had different genotypes at all 20 loci (data not shown). 'Burgaw(1)' had an SSR profile identical to 'Tarheel', and molecular profiles indicated it was not the parent of 'Albermarle', 'Chowan', or 'Dearing', as reported for 'Burgaw', indicating that this 'Burgaw(1)' is a misidentified 'Tarheel' vine. Pedigree analysis results of 'Burgaw(2)' were consistent with the parentage of 'Albermarle', 'Chowan', 'Topsail', 'Magoon', and 'Dearing' (Supplemental Table S1), strongly suggesting it is indeed 'Burgaw'. The 'Scuppernong' accessions collected from Concord, GA and McNeill, MS matched with 'Roanoke' at all loci. Additionally, these two vines were shown to have hermaphroditic flowers like 'Roanoke', whereas 'Scuppernong' has female flowers. Both 'Scuppernong' and 'Roanoke' produce mediumsized bronze berries, likely leading to the misidentification of the relatively rare 'Roanoke' as 'Scuppernong'. 'James' and the two accessions each of 'San Jacinto' and 'La Salle' shared a single marker profile. All three cultivars are older female cultivars with small, black berries, making them difficult to distinguish phenotypically. Both 'San Jacinto' and 'La Salle' are reported to be seedlings of 
'Scuppernong' (McLeRoy and Renfro, 2008), but their marker profile rules out 'Scuppernong' as a parent; therefore, all were listed as 'James', although this identification is only considered preliminary because only a single accession of 'James' could be found. The remaining six misidentifications (Table 2) also occurred between cultivars with a similar berry phenotype and represent the type of identification errors that plague most fruit cultivar collections.

'Arkansas 1' was submitted to the National Clonal Germplasm Repository (Davis, CA) as a wild accession of $V$. rotundifolia, but it proved to be a subgenus Vitis accession after its branched tendrils were observed at the research station of the University of Georgia (Tifton campus). Further phenotypic analysis determined that this accession is an unknown accession of Vitis cinerea (P.J. Conner, unpublished data). Therefore, 'Arkansas 1' was excluded from the genetic diversity analysis of Muscadinia. Three cultivars, Dulcet, Tara, and Triumph, have homonym accessions with differing genotypes that did not match any other genotypes in the dataset. Because only two 'Dulcet' accessions were available, and because there is no pedigree information available to indicate which accession is correct, these accessions were labeled as "unknown(1)" and "unknown(2)," and both accessions were included in the diversity analysis. 'Tara' and 'Triumph' both had single homonym accessions (Supplemental Table S1) among multiple accessions, and pedigree data were consistent with the outlier accessions being the off-type (Supplemental Table S1). Therefore, 'Tara(6)' and 'Triumph(6)' were listed as "unknown(3)" and "unknown(4)" in the genetic diversity analysis (Fig. 1).

Pedigree analysis. Several cultivars (Darlene, Early Fry, Fry Seedless, Hunt, Late Fry, Loomis, Magoon, November, Onslow, Pamlico, Scarlett, Spalding, and Stuckey) had at least one parent for which the reported pedigree is inconsistent with the molecular marker data (parent and potential progeny did not share at least one allele for all loci) (Supplemental Table S1). In many cases, the male parent tis inconsistent with the reported pedigree, which is not unexpected because it is easier to have accidental cross-pollination than it is to mix-up seeds or seedlings. Reported pedigrees indicated that 'Carlos' was the male parent of both 'Darlene' and 'Granny Val' (Brooks and Olmo, 1997). However, 'Darlene' did not share any common allele across four SSR loci with 'Carlos' (Supplemental Table S3), ruling out 'Carlos' as a parent. 'Fry' and 'Granny Val' are the reported parents of 'Late Fry', but SSR data indicated that 'Late Fry' is not a progeny of 'Granny Val' because the two genotypes do not share a common allele across six loci if the

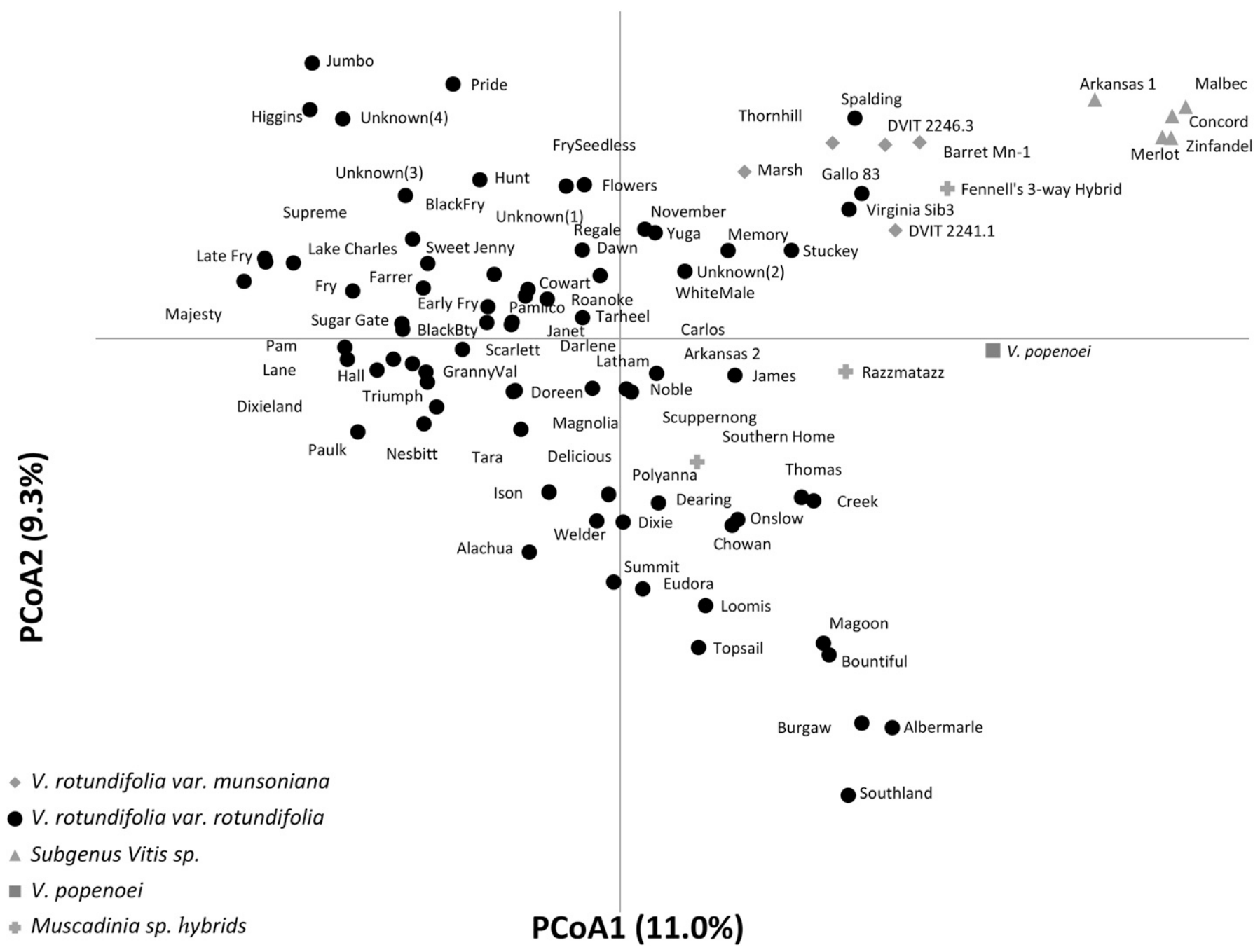

Fig. 1. Biplot derived from the principle coordinate analysis (PCoA) of the genetic distance matrix based on 20 simple sequence repeat (SSR) markers for 89 unique Vitis subgenus Vitis and subgenus Muscadinia genotypes. 
alleles of 'Fry' are considered. However, 'Cowart' was found to share alleles with 'Late Fry' across all 20 loci (Supplemental Table S3). Also, 'Cowart' is commonly used as a pollinizer in 'Fry' vineyards, thus increasing the likelihood that 'Cowart' is the male parent of 'Late Fry'. 'Burgaw' is the male parent of six cultivars, Albermarle, Chowan, Dearing, Magoon, Pamlico, and Topsail, in breeding records (Brooks and Olmo, 1997). However, the molecular profile of 'Burgaw' did not share an allele with 'Magoon' or 'Pamlico' at four and five loci, respectively, yet 'Burgaw' matched the other four cultivars at all loci, verifying Burgais is the not the parent of Magoon. The identity and pedigree of 'Pamlico' are preliminary because there was only one accession and this cultivar did not appear in other parentage-offspring relationships, making it difficult to confirm the identity of Pamlico from this dataset. 'Scarlett', which is reported to be the progeny of 'Summit' $\times$ 'Triumph' (Brooks and Olmo, 1997), has distinctive pink berries, making misidentification unlikely. However, 'Scarlett' did not share a common allele with 'Triumph' across six loci when the alleles provided by 'Summit' were considered, indicating that 'Triumph' is not a parent of 'Scarlett'.

The female parent was questioned in a few cultivars. 'Sweet Jenny' and 'Ison' are the reported parents of 'Early Fry' (Brooks and Olmo, 1997). However, 'Early Fry' did not share alleles with 'Sweet Jenny' or 'Ison' at five loci. Instead, SSR data indicated 'Fry' and 'Triumph' could be the parents of 'Early Fry'. 'Fry Seedless' is a unique cultivar with pink parthenocarpic seedless berries, with the reported pedigree of Farrer $\times$ Redgate. 'Farrer' was eliminated as a parent because it does not share an allele with 'Fry Seedless' at seven loci, and no other accessions in the data set were possible parents. No accessions of 'Redgate' were included in this study.

Some pedigree relationships should be considered preliminary until more accessions can be used to confirm these data. The profile of 'Scuppernong' suggested that it could not be the parent of three historical muscadine cultivars, November, Onslow, and Stuckey. However, each of these are rare historical cultivars that were only represented by a single accession located in the National Clonal Germplasm Repository collection and may not be authentic. The profile of 'Creek' was not consistent with being the parent of 'Loomis', as reported; however, the identity of 'Creek' is unconfirmed, with only one accession available in this study. Similarly, 'Flowers' was not consistent with being a parent of 'Hunt', but only a single 'Flowers' accession was available for testing. 'Loomis' was

Table 3. Summary statistics of muscadine (genetic diversity at four levels: cultivated accessions, current cultivars, historical cultivars, and wild accessions, including wild Vitis rotundifolia var. rotundifolia and $V$. rotundifolia var. munsoniana).

\begin{tabular}{lccccccc}
\hline & & & & \multicolumn{4}{c}{ Alleles (no.) } \\
\cline { 5 - 7 } Subgroup & $\mathrm{N}^{\mathrm{z}}$ & Mean $\mathrm{Ho}^{\mathrm{z}}$ & Mean $H e^{\mathrm{z}}$ & Total & Private $^{\mathrm{y}}$ & Unique $^{\mathrm{x}}$ & Mean \\
\hline Cultivated accessions & 67 & 0.72 & 0.69 & 154 & 50 & 9 & 7.70 \\
Current cultivars & 39 & 0.69 & 0.63 & 94 & - & - & 4.70 \\
Historical cultivars & 28 & 0.77 & 0.73 & 153 & - & - & 7.65 \\
Wild accessions & 9 & 0.71 & 0.78 & 172 & 68 & 18 & 8.60
\end{tabular}

$\overline{\mathrm{z}} \mathrm{N}=$ sample size $; H o=$ observed heterozygosity $=$ number of heterozygotes $/ \mathrm{N} ;$ and $H e=$ expected heterozygosity $=1-\operatorname{sum} p_{i}^{2}$; where $p_{i}$ is the population frequencies of the $i^{\text {th }}$ allele at a locus and $\mathrm{N}$ is the sample size.

${ }^{\mathrm{y}}$ Alleles detected only in that group.

${ }^{\mathrm{x}}$ Alleles detected only in one accession of all 76 genotypes in the diversity analysis. confirmed by its distinct phenotype, especially the burgundy red berry color and disease resistance.

'White Male' is a male vine used in early breeding programs for bronze cultivars. Breeding records reported it was the parent of 'Higgins', 'Hunt', 'Spalding', and 'Yuga'. However, none of these cultivars shared a common allele with the White Male accession in this data set across all the 20 loci. However, the name "White Male" was widely used to describe vines possessing green, unpigmented tendrils and male flowers, and it may have been more of a descriptive term than an actual particular selection. Therefore, it is unsurprising that the "White ale' collected from Tifton, GA, is not the accession used to 'Higgins', 'Hunt', 'Spalding', and 'Yuga' in early breeding programs. Riaz et al. (2008) discovered that the 'White Male' in the National Clonal Germplasm Repository collection was not the 'White Male' used to generate 'Yuga' and 'Higgins'.

Genetic Diversity for $\boldsymbol{V}$. Rotundifolia. Early muscadine breeding work was begun nearly simultaneously in North Carolina and Georgia in the beginning of the 20th century. Despite these programs having been developed independently, a similar narrow germplasm pool was used in both programs. The North Carolina program was developed with just seven female selections and a similar number of male selections as parents, nearly all of which were selected from the coastal plain region of North Carolina (Dearing, 1917; Newman, 1907). The University of Georgia breeding program was even more restricted, having begun with just three female and male selections (Stuckey, 1919). The female cultivars used by the Nersity of Georgia were all among those used in North ma, but the male vines are ambiguous because they were the male vine characteristics are indistinct. Excluding V. popenoei, three Muscadinia $\times$ Vitis hybrids, and four unidentified accessions, the analysis of tic diversity was conducted within $76 \mathrm{~V}$. rotundifolia ; four levels: all $V$. rotundifolia cultivars $(\mathrm{N}=$ wild $V$. rotundifolia var. rotundifolia and $V$. rotundifolia var. munsoniana) (Table 3). For 67 verified $V$. rotundifolia cultivars, the mean $\mathrm{He}$ was 0.69 , which was identical to the results of a previous muscadine genetic diversity study $(\mathrm{N}=35)$ (Riaz et al., 2008). The mean $H o$ was 0.72 , which was slightly lower an the measurements of Riaz et al. (2008). Comparing cultivated muscadines with wild $V$. rotundifolia accessions indicated that a total of 154 alleles were detected among the 67 muscadine cultivars, whereas a sum of 172 alleles was detected in only nine wild muscadine accessions. The average $H o$ was similar, but both the mean number of alleles (average number of alleles per locus) and the number of private alleles (alleles detected only in the subgroup) were higher for wild muscadines (8.60 and 68) than those for cultivated muscadines (7.70 and 50). The nine wild muscadine accessions conveyed a high level of genetic diversity that was higher or at least tantamount to the genetic diversity of the 67 cultivated 
muscadines. That only nine wild accessions could produce levels of diversity similar to those of 67 cultivated muscadines is unsurprising given the limited number and geographical range of selections used to initiate muscadine breeding. Additionally, wild muscadines are typically dioecious, producing a high level of heterozygosity in wild accessions, which is the primary factor contributing to the capture of a large amount of genetic diversity with such a small number of individuals (Charlesworth and Charlesworth, 1979; Ellstrand and Elam, 1993). Moreover, the wild accessions had a much larger number of unique alleles (alleles detected only in one accession). This is not unexpected because the wild accessions have seldom been used in breeding programs and are more likely to have rare alleles. In contrast, the cultivated accessions had many accessions, most of which were related to each other and thus would share alleles.

When comparing current cultivars $(\mathrm{N}=39)$ with historical ones $(\mathrm{N}=28)$, we found that the total of detected alleles and the mean number of alleles were both higher for historical cultivars, as are the mean $\mathrm{Ho}$ and mean $\mathrm{He}$ (Table 3). The higher level of genetic diversity for historical cultivars than that of current ones is expected because historical cultivars consist of plants selected from the wild or their immediate progeny. In more recent breeding programs, elite cultivars have been used extensively. For example, 'Fry' is viewed as the foundation of the modern muscadine industry (Conner, 2009), and a large percentage of current cultivars are derived from Fry (Supplemental Table S1). However, for 17 out of 20 studied loci, Ho was higher than $\mathrm{He}$ for current cultivars (data not shown), indicating that the set of current cultivars also represents a substantial diversity.

The PCoA shows clear separation among wild Muscadinia accessions, subgenus Vitis accessions, and cultivated muscadines with PCoA1 and PCoA2, explaining $11.01 \%$ and $9.26 \%$ of the total variation, respectively (Fig. 1). Subgenus Vitis cultivars are clustered together and distant from all the Muscadinia accessions, as expected. It was noticed that the historical cultivar Spalding appears close to the group of wild accessions including $V$. rotundifolia var. munsoniana and wild $V$. rotundifolia accessions, which is not unexpected because 'Spalding' is just one generation removed from a wild selection. $V$. popenoei is particularly separated from all $V$. rotundifolia accessions, which corresponds to its taxonomy as an independent species in Muscadinia.

CORE SET OF SSRs fOR CUltivar IDENTIFICATION. For the convenience of cultivar identification, a stepwise decrease in the number of markers based on their PIsibs value and PIC value (Table 1) was used to recognize the combination of the least markers with the ability to differentiate the most genotypes. With a core set of only four SSRs, VVIB23, VVMD27, VMC5b8, VMC4f3.1, all 79 unique muscadine genotypes were differentiated from each other except for 'Tara' and 'Alachua'. Adding any one additional marker from the seven (VMC5f1, VMC3d7, VVS2, VVIV67, VMC5a1, VMC8d11-1, and VMC8d11-2) enables 'Tara' and 'Alachua' to also be discriminated. Therefore, the core set of five SSR markers was able to achieve the goal of distinguishing cultivars with the smallest number of markers.

\section{Conclusions}

With 20 SSR loci to characterize 190 muscadine accessions, this study presents the most abundant DNA fingerprinting profile for muscadine grapes to date. The set of 20 Vitis-derived SSR markers enables the verification of 67 muscadine cultivars and two Muscadinia $\times$ Vitis hybrids, the identification of five unknown plants, and the discovery of 18 misidentifications. Conflicts between the reported pedigree and the molecular data were found for 13 cultivars. A core set of five SSR markers were highly efficient for identifying muscadine cultivars. This information is beneficial for curating muscadine germplasm and protecting the interests of breeders. Additional genotypic and phenotypic data are required to clarify pending identification questions encountered during this study. Although closely related cultivars are extensively used in breeding programs, there is a considerable amount of genetic diversity within current muscadine cultivars. This result corresponds to that of a previous report (Riaz et al., 2008). High levels of genetic diversity are indicated in historical cultivars and wild muscadines as well. There is increasing awareness of the value of old and wild germplasm for plant breeding. The high number of private alleles in the wild germplasm indicates that native muscadine accessions may harbor new traits of interest to breeding programs.

\section{Literature Cited}

Andersen, P., J. Mortensen, and J. Harris. 1998. 'Polyanna' muscadine grape. HortScience 33:166-167.

Bassil, N., A. Nyberg, K. Hummer, J. Graham, M. Dossett, and C. Finn. 2012. A universal fingerprinting set for red raspberry. Acta Hort. 946:83-87.

Blacket, M., C. Robin, R. Good, S. Lee, and A. Miller. 2012. Universal primers for fluorescent labelling of PCR fragments-an efficient and cost-effective approach to genotyping by fluorescence. Mol. Ecol. Resour. 12:456-463.

Blanc, S., S. Wiedemann-Merdinoglu, V. Dumas, P. Mestre, and D. Merdinoglu. 2012. A reference genetic map of Muscadinia rotundifolia and identification of Ren5, a new major locus for resistance to grapevine powdery mildew. Theor. Appl. Genet. 125:1663-1675.

Boursiquot, J., T. Lacombe, V. Laucou, S. Julliard, F.-X. Perrin, N. Lanier, D. Legrand, C. Meridith, and P. This. 2009. Parentage of Merlot and related winegrape cultivars of southwestern France: Discovery of the missing link. Aust. J. Grape Wine Res. 15:144-155. Botstein, D., R.L. White, M. Skolnick, and R.W. Davis. 1980. Construction of a genetic-linkage map in man using restriction fragment length polymorphisms. Amer. J. Hum. Genet. 32:314-331. Bowers, J., J. Boursiquot, P. This, K. Chu, H. Johansson, and C. Meredith. 1999. Historical genetics: The parentage of 'Chardonnay', 'Gamay', and other wine grapes of northeastern France. Science 285(5433):1562-1565.

Brooks, R. and H. Olmo. 1997. Brooks and Olmo register of fruit \& nut varieties. 3rd ed. ASHS Press, Alexandria, VA.

Charlesworth, D. and B. Charlesworth. 1979. The evolutionary genetics of sexual systems in flowering plants. Proc. R. Soc. Lond. 205:513-530.

Cipriani, G., M. Marrazzo, R. Marconi, A. Cimato, and R. Testolin. 2002. Microsatellite markers isolated in olive (Olea europaea L.) are suitable for individual fingerprinting and reveal polymorphism within ancient cultivars. Theor. Appl. Genet. 104:223-228.

Conner, P. 2009. A century of muscadine grape (Vitis rotundifolia Michx.) breeding at the University of Georgia. Acta Hort. 827:481484.

Conner, P. 2013. 'Lane': An early-season self-fertile black muscadine Grape. HortScience 48:128-129.

Conner, P. 2014. 'Hall': An early-season self-fertile bronze muscadine grape. HortScience 49:688-690.

Conner, P. 2017. 'Paulk': A muscadine grape with hermaphroditic flowers and large berries. HortScience 52:1639-1641. 
Conner, P., J. Conner, P. Catotti, J. Lewter, J. Clark, and L. Biasi. 2017. Development and characterization of molecular markers associated with female plants in muscadine grape. J. Amer. Hort. Sci. 142:143150.

Dangl, G., M. Mendum, B. Prins, M. Walker, C. Meredith, and C. Simon. 2001. Simple sequence repeat analysis of a clonally propagated species: A tool for managing a grape germplasm collection. Genome 44:432-438.

Dangl, G., K. Woeste, M. Aradhya, A. Koehmstedt, C. Simon, D. Potter, C. Leslie, and G. McGranahan. 2005. Characterization of 14 microsatellite markers for genetic analysis and cultivar identification of walnut. J. Amer. Hort. Sci. 130:348-354.

Dearing, C. 1917. The production of self-fertile muscadine grapes. Proc. Amer. Soc. Hort. Sci. 14:30-34.

Dearing, C. 1948. New muscadine grapes. U.S. Dept. Agr., Washington, DC.

Doligez, A., A. Adam-Blondon, G. Cipriani, G. Di Gaspero, V. Laucou, D. Merdinoglu, C. Meredith, S. Riaz, C. Roux, and P. This. 2006. An integrated SSR map of grapevine based on five mapping populations. Theor. Appl. Genet. 113:369-382.

Di Gaspero, G., E. Peterlunger, R. Testolin, K. Edwards, and G. Cipriani. 2000. Conservation of microsatellite loci within the genus Vitis. Theor. Appl. Genet. 101:301-308.

Ellstrand, N.C. and D.R. Elam. 1993. Population genetic consequences of small population size: Implications for plant conservation. Annu. Rev. Ecol. Syst. 24:217-242.

Fossati, T., I. Zapelli, S. Bisoffi, A. Micheletti, L. Vietto, F. Sala, and S. Castiglione. 2005. Genetic relationships and clonal identity in a collection of commercially relevant poplar cultivars assessed by AFLP and SSR. Tree Genet. Genomes 1:11-20.

Franks, T., R. Botta, M. Thomas, and J. Franks. 2002. Chimerism in grapevines: Implications for cultivar identity, ancestry and genetic improvement. Theor. Appl. Genet. 104:192-199.

Goldy, R. and O. Onokpise. 2002. Genetics and breeding, p. 51-90. In: F.M. Basiouny and D.G. Himelrick (eds.). Muscadine grapes. ASHS Press, Alexandria, VA.

Gray, D. 2009. 'Delicious': An early-ripening, self-fertile, multipurpose black-fruited muscadine grape. HortScience 44:200-201.

Hearne, C., S. Ghosh, and J. Todd. 1992. Microsatellites for linkage analysis of genetic traits. Trends Genet. 8:288-294.

Hedrick, U.P., N.O. Booth, M.J. Dorsey, O.M. Taylor, and R. Wellington. 1908. The grapes of New York. JB Lyon, Albany, NY. Huang, H., J. Lu, Z. Ren, W. Hunter, S. Dowd, and P. Dang. 2011. Mining and validating grape Vitis L. ESTs to develop EST-SSR markers for genotyping and mapping. Mol. Breed. 282:241-254.

Husmann, G. and C. Dearing. 1913. The muscadine grapes. U.S. Dept. Agr. Bul. 273.

Husmann, G. and C. Dearing. 1916. Muscadine grapes. U.S. Dept. Agr. Farmer's Bul. 709.

Ingrouille, M.J., M.W. Chase, M.F. Fay, D. Bowman, M. Van Der Bank, and A.D.E. Bruijn. 2002. Systematics of Vitaceae from the viewpoint of plastid $r b c L$ DNA sequence data. Bot. J. Linn. Soc 138:421-432.

Liu, X.-Q., S.M. Ickert-Bond, Z.-L. Nie, Z. Zhou, L.-Q. Chen, and J. Wen. 2016. Phylogeny of the Ampelocissus-Vitis Glade in Vitaceae supports the New World origin of the grape genus. Mol. Phylogenet. Evol. 95:217-228.

Lu, J., R. Zhong-bo, and X. Xu. 2008. Muscadine grape plant named 'Majesty'. U.S. Plant Patent 21965P3. Filed 15 Apr. 2008. Issued 7 June 2011.

McLeRoy, S. and R. Renfro. 2008. Grape man of Texas: The life of T.V. Munson. Eakin Press, Austin, TX.

Merdinoglu, D., G. Butterlin, L. Bevilacqua, V. Chiquet, A. AdamBlondon, and S. Decroocq. 2005. Development and characterization of a large set of microsatellite markers in grapevine Vitis vinifera L. suitable for multiplex PCR. Mol. Breed. 154:349-366.

Moore, M.O. 1991. Classification and systematics of eastern North American Vitis L. (Vitaceae) north of Mexico. Sida 14:339-367.
Mortensen, J., J. Harris, D. Hopkins, and P. Anderson. 1994. 'Southern Home': An interspecific hybrid grape with ornamental value. HortScience 29:1371-1372.

Mortensen, J.A. 2001. Cultivars, p. 91-105. In: F.M. Basiouny and D.G. Himelrick (eds.). Muscadine grapes. ASHS Press, Alexandria, VA.

Munson, T.V. 1909. Foundations of American grape culture. T.V. Munson \& Son, Denison, TX.

National Center for Biotechnology Information. 2005. Vitis Microsatellite Consortium. 20 July 2017. <https://www.ncbi.nlm.nih.gov/ nuccore/?term=Vitis\%20Microsatellite\%20Consortium>.

Nei, M. 1987. Molecular evolutionary genetics. Columbia Univ. Press, New York, NY.

Newman, C.C. 1907. Rotundifolia grapes. South Carolina Agr. Expt. Sta. Bul. 132.

Nybom, H., K. Weising, and B. Rotter. 2014. DNA fingerprinting in botany: Past, present, future. Investig. Genet. 5:1.

Olien, W.C. 1990. The muscadine grape: Botany, viticulture, history, and current industry. HortScience 25:732-739.

Olien, W.C. 2002. Introduction to the muscadines, p. 1-13. In: F.M. Basiouny and D.G. Himelrick (eds.). Muscadine grapes. ASHS Press, Alexandria, VA.

Patel, G.I. and H.P. Olmo. 1955. Cytogenetics of Vitis L.: The hybrid $V$. vinifera $\times V$. rotundifolia. Amer. J. Bot. 42:141-159.

Peakall, R. and P. Smouse. 2012. GenAlEx 6.5: Genetic analysis in Excel. Population genetic software for teaching and research-an update. Bioinformatics 28:2537-2539.

Pellerone, F., K. Edwards, and M. Thomas. 2001. Grapevine microsatellite repeats: Isolation, characterization and use for genotyping of grape germplasm from southern Italy. Vitis 404:179-186.

Pelsy, F. 2007. Untranslated leader region polymorphism of $T v v 1$, a retrotransposon family, is a novel marker useful for analyzing genetic diversity and relatedness in the genus Vitis. Theor. Appl. Genet. 116:15-27.

Planchon, J. 1887. Monographie des Ampélidées vraies, p. 305-654. In: A.E.P.P. de Condolle and C. de Candolle (eds.). Monographiae phanerogamarum. Masson, Paris, France.

Reimer, F.C. 1909. 'Scuppernong' and other muscadine grapes: Origin and importance. North Carolina Agr. Expt. Sta. Bul. 201.

Riaz, S., A. Tenscher, B. Smith, D. Ng, and M. Walker. 2008. Use of SSR markers to assess identity, pedigree, and diversity of cultivated muscadine grapes. J. Amer. Hort. Sci. 133:559-568.

Riaz, S., R. Hu, and M.A. Walker. 2012. A framework genetic map of Muscadinia rotundifolia. Theor. Appl. Genet. 125(6):11951210.

Schwartz, K. 1976. The origin and development of muscadine grape varieties. Fruit Var. J. 30:90-92.

Sefc, K.M., F. Regner, E. Turetschek, J. Glössl, and H. Steinkellner. 1999. Identification of microsatellite sequences in Vitis riparia and their applicability for genotyping of different Vitis species. Genome 423:367-373.

Semagn, K., A. Bjornstad, and M. Ndjiondjop. 2006. An overview of molecular marker methods for plants. Afr. J. Biotechnol. 5:25402568.

Slate, J., T. Marshall, and J. Pemberton. 2000. A retrospective assessment of the accuracy of the paternity inference program CERVUS. Mol. Ecol. 9:801-808.

Smouse, P. and R. Peakall. 1999. Spatial autocorrelation analysis of individual multiallele and multilocus genetic structure. Heredity 82:561-573

Steffens, D.L., S.L. Sutter, and S.C. Roemer. 1993. An alternate universal forward primer for improved automated DNA sequencing of M13. Biotechniques 15:580-582.

Stringer, S. 2011. 'Eudora' muscadine grape. HortScience 46:143144.

Stuckey, H.P. 1919. Work with Vitis rotundifolia: A species of muscadine grapes. Georgia. Expt. Sta. Bul. 133. 
Thomas, M., P. Cain, and N. Scott. 1993. DNA typing of grapevines: A universal methodology and database for describing cultivars and evaluating genetic relatedness. Plant Mol. Biol. 256:939-949.

This, P., T. Lacombe, and M. Thomas. 2006. Historical origins and genetic diversity of wine grapes. Trends Genet. 22:511-519.

Trujillo, I., M. Ojeda, N. Urdiroz, D. Potter, D. Barranco, L. Rallo, and C. Diez. 2014. Identification of the worldwide olive germplasm bank of Córdoba (Spain) using SSR and morphological markers. Tree Genet. Genomes 10:141-155.

Van Oosterhout, C., W. Hutchinson, D. Wills, and P. Shipley. 2004. MICRO-CHECKER: Software for identifying and correcting genotyping errors in microsatellite data. Mol. Ecol. Notes 4:535538.

Wang, Z., Y. Wu, D. Martin, H. Gao, T. Samuels, and C. Tan. 2010. Identification of vegetatively propagated turf bermudagrass cultivars using simple sequence repeat markers. Crop Sci. 50:2103-2111.
Wen, J. 2007. Vitaceae, p. 466-478. In: J.W. Kadereit (ed.). The families and genera of vascular plants. Springer, Berlin, Germany. Wen, J., L.-M. Lu, Z.-L. Nie, X.-Q. Liu, N. Zhang, S. Ickert-Bond, J. Gerrath, S.R. Manchester, J. Boggan, and Z.-D. Chen. 2018. A new phylogenetic tribal classification of the grape family (Vitaceae). J. Syst. Evol. 56:262-272.

$\mathrm{Xu}, \mathrm{K}$. , S. Riaz, N. Roncoroni, Y. Jin, R. Hu, R. Zhou, and M. Walker. 2008. Genetic and QTL analysis of resistance to Xiphinema index in a grapevine cross. Theor. Appl. Genet. 1162:305-311.

Zecca, G., J.R. Abbott, W.-B. Sun, A. Spada, F. Sala, and F. Grassi. 2012. The timing and the mode of evolution of wild grapes (Vitis). Mol. Phylogenet. Evol. 62:736-747.

Zurn, J., K. Carter, M. Yin, M. Worthington, J. Clark, C. Finn, and N. Bassil. 2018. Validating blackberry seedling pedigrees and developing an improved multiplexed microsatellite fingerprinting set. J. Amer. Hort. Sci. 143:381-390. 